\title{
FRAMEWORK DEVELOPMENT FOR DYNAMIC SYSTEM VALIDATION
}

Eylül Damla GÖNÜL SEZER*, Industrial Engineering Department, Yeditepe University, Turkey, eylul.sezer@yeditepe.edu.tr (iD) https://orcid.org/0000-0002-9237-0468)

Zeynep OCAK, Industrial Engineering Department, Yeditepe University, Turkey, zocak@yeditepe.edu.tr (iD) https://orcid.org/0000-0002-2830-7851)

\begin{abstract}
Validation is one of the most important stages of modeling, and it is a necessity before utilizing the model for further analyses. Especially for the studies that start with conceptual models, the validation process is more complex than others. In this study, we used a multi-methodology approach to develop a framework to support the conceptual model development and validation in System Dynamics (SD) modeling. In the proposed framework, we integrated methods from SD methodology with methods from the Analytic Network Process (ANP). The proposed framework was then used for clinical laboratory performance analysis. The purpose was to use the proposed framework to conduct structural validity of the SD model, to prioritize Clinical Laboratory (CL) performance indicators, and capture their relations. Results indicate that the proposed framework can be used to generate an enriched and validated conceptual model for a CL performance system that can be useful for healthcare decision-makers. Also, the proposed multi-methodology framework can be applied to any complex systems to validate the conceptual models.
\end{abstract}

Keywords: System Dynamics; Conceptual Model Development; Analytic Network Process; Validation

\section{DİNAMİK SISSTEM GEÇERLİLİĞİ İÇİN ÇERÇEVE GELİSTTİRME}

\section{Özet}

Geçerlilik, modellemenin en önemli aşamalarından biridir ve her model için gereklidir. Bu süreç, özellikle kavramsal modeller ile başlanılan çalışmalarda diğerlerine nazaran daha karmaşıktır. Kavramsal model geliştirmenin sistem dinamiği (SD) modellerinin doğrulanması ve geçerlilik analizlerinin sonuçları üzerinde büyük etkisi olduğu öne sürülmektedir. Bu çalışmada, SD modellemesinde kavramsal model geliştirme ve geçerlilik sürecini destekleyen bir çerçeve geliștirmek için çoklu metodoloji yaklaşımı kullanılmıștır. Önerilen çerçevede, SD metodolojisindeki yöntemler Analitik Ağ Süreci (ANP) yöntemleriyle entegre edilmiştir. Önerilen çerçeve daha sonra klinik laboratuvarda performans analizi için kurulacak bir SD modelinin onaylanması için kullanılmıştır. Amacımız, SD modelinin yapısal geçerliliğini gerçekleştirmek, klinik laboratuvar performans göstergelerinin hangilerine önceliklendirmek ve bunların ilişkilerini yakalamak için önerilen çerçeveyi kullanmaktır. Sonuçlar, önerilen çerçevenin, sağlık hizmeti karar vericileri için yararlı olabilecek bir klinik laboratuvar performans sistemi için zenginleștirilmiş ve doğrulanmış bir kavramsal model oluşturmak için kullanılabileceğini göstermektedir. Ayrıca, önerilen çoklu metodoloji çerçevesi, kavramsal modellerin doğrulama ve onaylanması için başka sistemlere de uygulanabilir.

Anahtar Kelimeler: Sistem Dinamiği, Nedensel/Kavramsal Model Geliștirme, Analitik Ağ Süreci, Geçerlilik

Cite

Gönül Sezer, E.D. and Ocak, Z. (2020). “Framework development for dynamic system validation”, Mugla Journal of Science and Technology, 6(2), 140-149.

\section{Introduction}

System Dynamics (SD) simulation models are often used for developing system operating policies, and to understand system behaviors. The stakeholders of these models are concerned with whether a model and its outputs are 'correct' for its use. This concern is addressed through model validation. Model validation is defined as the 'substantiation that a model within its domain of applicability possesses a satisfactory range of accuracy consistent with the intended application of the model' [1].
There are two types of tests to establish model credibility [2]. One of them is the structural validation test to validate the conceptual model. In other words, to determine whether the structure of the model is a meaningful description of the real relations that exists in the system. The other one is behavior tests to test whether the dynamic patterns generated by the model are close enough to the real dynamic patterns of the system. However, the behavior test is meaningful only after the structure of the model is validated. Thus, for any dynamic model initially, the validity of the structure 
should be confirmed, and the behavior accuracy should be only tested after the structure of the model is validated. To this extend, this paper concentrates only on structural validation.

As the complexity of simulations increased during the past decade, the importance of conceptual model development and validation for SD simulation models have been emphasized greatly [3]. Conceptual models formalize a system designer's idea as a step to generate a final dynamic model. They reflect the beliefs, values, assumptions, and underline the reasons for doing them $[4,5]$. At the same time, it helps stakeholders to understand how objectives can be achieved based on strategically linked measures (variables). Conceptual models should be sufficiently rich to allow for the main influencing factors to be satisfactorily included [6]. Therefore, it is important to verify the content and validity of the conceptual model before it is used any further. One way of ensuring this validity is through the use of incremental development, which includes starting with initial simple conceptual model development and slowly adding richness to the model as per requirements from stakeholders [7]. It is clear that understanding and interpreting the focus of stakeholders are critically important during the conceptual model development. However, in some cases, modelers may not manage the interviews or group decision making sessions, to eliminate misunderstandings or loss of information, this study proposes to use Analytic Network Process (ANP). In other words, in this study ANP method is used 1) to capture the various stakeholders' judgments and viewpoints about the system indicators proposed in the conceptual model and 2) to validate interrelations and dependencies (causal relationships) among these indicators.

Causal relationships are the fundamental elements of a conceptual (mental) model [4]. These causal relationships must be enriched with different points of view, and eventually, these causal links (relationships) are finalized for a conceptual model. Additionally, for the structural validation of the SD model, a common causal relationship is needed to validate the finalized conceptual model. To satisfy it, this paper proposes a multi-methodology framework that combines ANP and SD methodologies to support the conceptual model development (Causal Loop Development (CLD), and structural validation in SD modeling. Judgments and comments of the experts collected through ANP study are utilized for boundary adequacy, structure, and parameter verification stages of structural validity testing. With the help of this study, modelers will utilize the framework as a guideline to include stakeholder participation and facilitation during the conceptual model development and system validation stages. It generates a clear direction to interviews and serves as a backcheck mechanism for the validation stage after model development. Additionally, in this paper, the proposed framework is applied to a healthcare system problem to develop and validate the conceptual model of the problem. Healthcare systems are complex and procedures vary in different specialties under the healthcare system. It may be difficult to manage interviews for modelers from different disciplines, since various procedures, standards, and processes inherent nature of healthcare systems, Therefore, a healthcare system application is chosen for the case study to show how the proposed framework guides and supports the modelers.

The outline of the paper is as follows; in Section 2, SD and ANP methodologies are described, and a proposed framework is presented in detail. Section 3 is devoted to the application of the proposed framework for a clinical laboratory (CL) case study. A discussion of the main findings, conclusion, and future work related to the study is given in Section 4 and 5.

\section{Methodology}

Multi-methodology approach provides methods and tools to increase the modelers' ability to handle complex problem situations and/or systems. It offers the feasibility of mixing methodologies from different paradigms. It is believed that individual methodologies may not be sufficiently equipped to support various stages in an intervention [8]. Thus, by combining methodologies or parts of methodologies in a single intervention, their support capabilities complement each other and create even more benefits to the system. Multi-methodology enables modelers to better capture the complexity of the system and to deploy the most appropriate methodology for the system design [9].

Since this paper offers a multi-methodology approach that combines ANP and SD modeling techniques, in sections 2.1 and 2.2, SD and ANP methodologies are presented in detail, followed by the proposed multimethodology framework.

\subsection{System Dynamics Modeling}

SD is a simulation method introduced by Jay Forrester in the mid-1950s. The method enables the modeler to analyze the dynamic behavior of complex systems. It has been utilized for social, socio-economic, engineering problems to analyze and understand both qualitative and quantitative factors behavior over time. There are five formal steps to develop a model with systems thinking and modeling perspective [10].

1. Problem articulation: In this initial step, the situation or issue at hand is defined and the scope and boundaries of the study are identified. In this step objectives and key variables are identified.

2. Formulation of Dynamic Hypothesis (Conceptual Model Development): In this step, the initial hypothesis and conceptual models of the problem, known as causal loop diagrams (CLD) are created. CLD is an illustrative method that enables the modelers to interpret causal relations among model variables. First, it is important to ensure that a causal relationship exists. Once it is established that such a causal relationship exists, it is necessary to know how the variables are related. The 
direction of the relationship between variable $A$ and variable $B$ is captured while other system variables are kept constant. If an increase-decrease on variable $\mathrm{A}$ causes an increase-decrease in variable $B$, their relationship is in the same direction. If an increasedecrease on variable A causes a decrease-increase in variable $B$, their relationship is in the opposite direction. Relationships in the same direction are mapped with a positive sign "+". While a negative sign "-" indicates that the relationship is in the opposite direction. In the end, all mapped relationships and the directions of these relationships are shown on CLDs. The qualitative model is obtained by mapped relationships.

3. Formulation of a Simulation Model: Although it is possible to go into this step directly after problem structuring, developing a causal loop model first will enhance the conceptual model and learning power of the systems approach [11]. The completeness and deeper insights of SD simulation are mostly absent in other simulation modeling approaches, where CLD is not used. Dynamic simulation model development encourages the researchers to understand a complex system's inner dynamics [12]. At this stage, the constituent variables on CLD are first classified as either stock or flow variables. Stocks indicate an accumulation, condition, or answer of "how things are?", whereas flow indicates "how things are going?" Then, causal relationships that are developed at previous stages are converted into stock-flow diagrams. Finally, a simulation model should be constructed by software based on stock-flow diagrams.

4. Testing: Validation is expressed as a key measurement to bear out the proposed model [13]. The main concern in validation is that stakeholders of the developed model are concerned with whether a model and its outputs are "correct" for its use. Validation in SD models is confirmed in two ways; structural and behavioral validity. In structural validity, the model structure is examined to ensure agreement with the existing relationships in real life. At this initial stage, modelers deal with their problem definition, model variables, and causal relationships among these variables (conceptual model). Thus, formal structural validation has five main stages. These are boundary adequacy, structure verification, parameter verification, dimensional consistency, and extreme condition tests [2]. In this study, the proposed framework is used for boundary adequacy, structure, and parameter verification tests under structural validity.

On the other hand, the quantitative model is checked in the behavioral validity phase. Behavior validity ensures that the model and the real system produce similar output behaviors. It must be noted that in causaldescriptive modeling, the essence of validity is structure validity: without a valid structure, output behavior validity will be meaningless [6]. Therefore, in the case of invalid models or unexpected results, the model should be reviewed starting from structural validity. If the structural validity is not ensured, the behavioral validity of the model is impaired as well.

5. Policy design and evaluation: Evaluating alternatives and making changes to the real system is not practical. Therefore, the best way to consider is to make changes to the simulation model to see the results of selected interventions. The changes can be applied to a single variable (policy analysis) or a set of variables to generate a special situation (strategy). Key drivers of changes, uncertainties, and factors are identified and their impact on the output is evaluated. This provides us to understand the behaviors of the system in detail.

\subsection{Analytic Network Process}

Many researchers in different fields have used decisionmaking methods to determine which alternative is the best for various problems such as facility location, machinery selection, information systems selection, and etc. Multi-criteria decision making has various approaches for prioritizing multiple factors to make decisions. Analytic Hierarchy Process (AHP) is the most famous decision-making approach, invented by Saaty $[14,15]$. Although this method is well known and frequently used, for some cases it is not sufficient. The AHP approach generates solutions for goals by comparing various criteria for alternatives. In this method, criteria relationships are not considered. To overcome this problem, Saaty invented a modified process called ANP. In contrast with AHP, the ANP approach utilizes relationships among various criteria in the model. ANP is accepted as a tool including both qualitative and quantitative criteria as a generalization of AHP $[14,16]$. The approach aims to analyze the influence of variables (criteria) with pairwise comparison matrices judged by experts. Similar to the AHP method, the scale of judgment in the pairwise comparison matrix has nine decision points for linguistic values. Saaty's scale asks of the dependent criteria, which one influences the common criteria more and how much more?" The corresponded numbers for these linguistic judgments are given in Table 1.

Table 1. Values of linguistic judgments.

\begin{tabular}{cc}
\hline Scale Value & Meaning \\
\hline 1 & Equal importance \\
\hline 3 & Moderate importance \\
\hline 5 & Strong importance \\
\hline 7 & $\begin{array}{l}\text { Very strong } \\
\text { importance }\end{array}$ \\
\hline 9 & $\begin{array}{c}\text { Extreme importance } \\
\text { Intermediate values }\end{array}$ \\
\hline
\end{tabular}

The generalization property of ANP comes from the pairwise relation matrix. This matrix enables decisionmakers to capture inner and outer relationships between the clusters and among the variables. Thus, networks and links are accepted as important elements in the ANP approach. In this study, the ANP process is examined under three stages: 
-Stage 1 (Model construction): All variables that affect the laboratory performance are determined and grouped into clusters for the network. These variables will be defined in section 3 . These influential variables are named as criteria and grouped based on their similarities to form a cluster.

-Stage 2 (Paired comparison among the clusters/variables): In the network, the outer dependencies (between clusters) and inner dependencies (among variables) are indicated by links. To do so, the following paired comparisons are performed, and a supermatrix is formed.

a) Cluster comparison: Paired comparisons are performed on the clusters with respect to the goal. Weights derived from this analysis are used to weigh the factors in the supermatrix column blocks.

b) Comparison of variables: Paired comparisons are performed on the variables within the clusters. Each variable in a cluster is compared based on its influence on a variable in its own cluster or on another variable in another cluster.

Decision analysts compute the geometric means of all paired-comparison judgments of different decisionmakers for each criterion to reveal the aggregated group judgments. To analyze aggregated judgments, all necessary calculations are done by Super Decisions software (developed by Saaty).

-Stage 3 (Supermatrix construction): Stage 2 generates an un-weighted supermatrix, where its columns contain pairwise comparison results. To obtain a weighted supermatrix, the blocks of the un-weighted supermatrix are multiplied by the corresponding cluster priority. Then the weighted supermatrix is raised until it is converged to capture first, second, and higher degree influences. The output is used to identify priorities.

\subsection{Proposed Framework for the Study}

In order to meet the objective of this research, a multimethodology framework (Figure 1) is proposed. In this framework, at first, the key variables of the selected problem are identified (problem articulation, explained in detail in section 3.1). These key variables are then utilized to develop an initial CLD for the SD model (conceptual model development, explained in detail in section 3.2). At the same time, the variables are used for ANP model construction (explained in detail in section 3.3). In other words, "conceptual model development" and "ANP model construction" phases are performed simultaneously. Pairwise relation results from ANP (explained in section 3.4) are then used to ensure the structural validity of the model (explained in section 3.5). Necessary modifications on the CLD are then performed to generate a revised conceptual model. Boundary adequacy, structure and parameter verification, dimensional consistency, and extreme condition tests are relevant and necessary parts of structural validity [10]. Thus, the proposed framework also recommends boundary adequacy, structure, and parameter verification analyses under structural validation. Dimensional consistency and extreme conditions tests are performed after the dynamic model is developed.

It should be noted all grey boxes in Figure 1; "formulating a simulation model" in SD methodology and "overall weights of key variables" and "alternative selection" in ANP methodology are out of the scope of this study. Thus, once the conceptual model is revised based on pairwise relation results from the ANP, our purpose for this research is achieved. Although the relative weights of criteria are not used in validation, the results of the overall weights of the main variables are given in this paper because they can be utilized for the policy analysis stage of SD.

Another important point in Figure 1 is that the bold arrows present a closed-loop between CLD development and structural validity boxes. In some cases, we detect that the model is not valid for its purpose in the first iteration. The framework gives us a chance to revise the model. If we detect that a model is still not valid for its purpose, the framework suggests the modelers make changes on previous CLD, and conduct the validation analysis again.

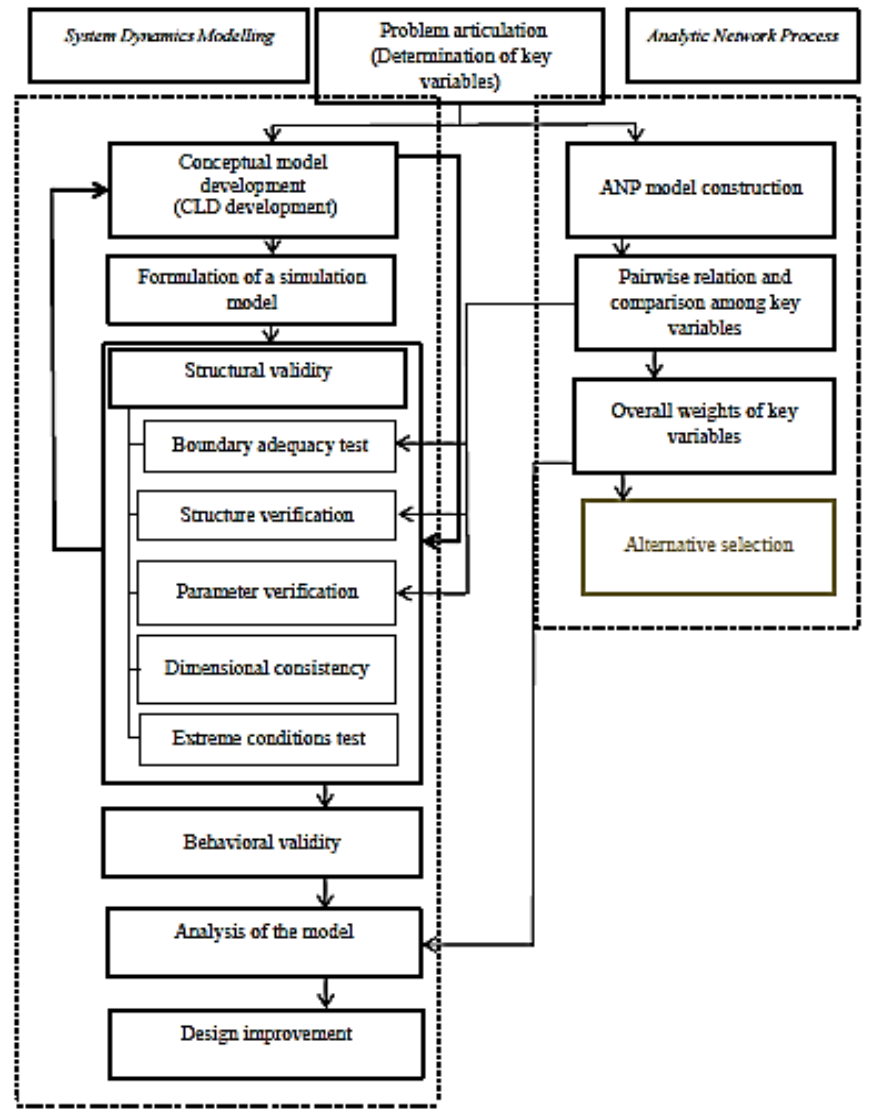

Figure 1. The proposed framework to conduct structural validity in SD modeling.

3. Case Study

In this section, the proposed framework is applied to a CL performance management system.

\subsection{Problem Articulation}

In this research, the performance of a CL is initially captured through efficiency and effectiveness. In 
literature, effectiveness and efficiency are discussed as two main factors to measure the performance of a CL system [17].

Effectiveness of a healthcare service is expressed as the degree of accomplishing planned outcomes by accurately following correct procedures in a given time period $[18,19]$. This accuracy does not only mean the reliability of test results, but it also means meeting the specific purposes of patients and tracing the right procedure to attain the service [20-22]. This means time and quality are the main indicators of effectiveness.

On the other hand, efficiency is defined as targeting to get the necessary output with minimum input. In addition to this definition, efficiency for healthcare systems is described as determining the level of resources to fulfill the health care service objectives [23]. In this case, costs in CL and management of the resources become a focal point for efficiency.

The given definitions of efficiency and effectiveness show that cost, quality, resource management, and time are the main indicators for efficiency and effectiveness. Thus, in this study, these four elements are used as the key variables for the performance measurement of a CL. These variables have been determined with literature survey, and also experts have been asked to add any other variable(s) that are not listed in the model for CL performance during the initial interview.

Cost: Estimation of the total monetary burden of the testing process is essential to make a judgment about the efficiency of a CL. The cost of testing is handled under the variable and fixed cost accounting approach. These costs generate four levels in CL cost analysis. These are workstation prime cost (depreciation costs, maintenance, cost of time and errors), direct labor cost, test material cost (cost of used reagents, kits, and other instruments), and overhead cost [24]. As part of the workstation cost, the cost of exceeding the tolerable cycle time per test, and rework cost are considered. Overhead costs (rent of the building, cost of heating, legal fees, taxes, and utilities) vary depending on the country; even CLs in different cities in the same country may have different overhead costs. Since this research aims to develop a general model for CL performance, overhead costs are not included in this study. The main elements under cost are defined as the cost of consumables, cost of quality, cost of labor, cost of equipment, and penalty cost due to late or wrong test results.

Quality: CLs are an integrated part of healthcare organizations. Produced test results in CLs are used in pre-diagnose, diagnose, monitoring, and controlling phases of health problems. Thus, errors occurring at any stage may lead to wrong decisions on patients' health problems. Based on the declaration of the International Standard for CL Accreditation [25]; "quality indicators can measure how well an organization meets the needs and requirements of users and the quality of all operational processes" $[25,26]$. Therefore, detected and undetected errors during the pre-analytical, analytical, and post-analytical stages, accidents during testing, late delivery of test results are accepted as the indicators for CL quality measurement.

Resource management: Based on the specifications of the Joint Commission on Accreditation of Healthcare Organizations (JCAHO), laboratory managers are responsible for planning and providing that resource utilization is properly arranged and the goals of the organization are met [27]. These specifications also include providing available and trained staff and materials (reagents, equipment, consumables, and all analytic systems) for testing procedures. Therefore, deciding on the staff level, type, and duration of the training program for new hires, ordering consumables for testing equipment, and maintenance periods of equipment are mainly related to resource utilization in a CL.

Inventory control: ordering and consumption of reagents and kits, mean time between failures (MTBF), maintenance and workload on machines (equipment), and workload on staff are selected as resource management indicators.

Time: Total cycle time in a CL is defined as the total time required for completing a testing procedure; it is called test Turnaround Time (TAT). It includes the cumulative time from the test order to delivering the report to the patient [28]. Each type of test has a different but standard cycle time, and patients are informed about expected report delivery time based on a testing procedure's standard time. In many CLs, delays on test delivery time are considered major issue [29]. Delays in required/standard TAT are accepted as a major problem leading to performance deficiency [30]. Bottlenecks must be found to overcome this performance problem. Time-related variables are chosen as order entry process time, specimen collection and delivery time, testing process time, reporting process time, and accession (recording of report deliverables) time.

\subsection{Conceptual Model Development}

The key variables of the system, determined as cost, quality, resource management, and time, are utilized to develop the initial conceptual model. Based on the relationships among these variables and sub-variables, the initial conceptual model of a CL performance management system is developed as shown in Figure 2.

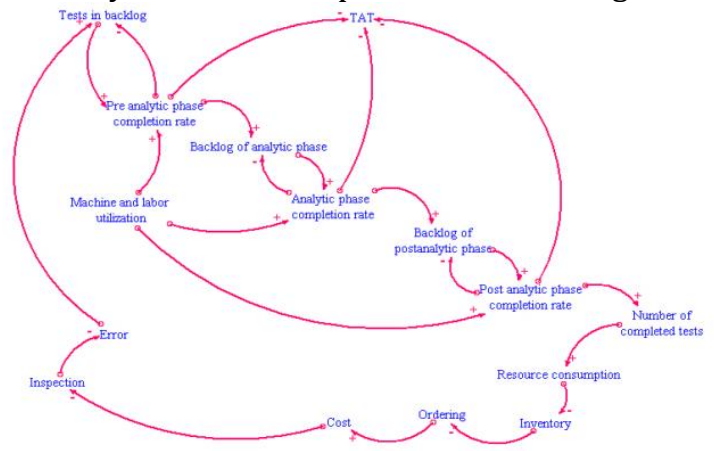

Figure 2. Initial conceptual model of the CL performance system. 


\subsection{ANP Model Development}

The main variables that are influential on CL performance were defined in the previous section as cost, quality, time, and resource management. These variables are called clusters for the ANP into criteria (variable) to develop a network for our goal. The list and definition of variables under each cluster are given in Table 2 .

Table 2. Names and explanations of criteria.

\begin{tabular}{|c|c|}
\hline $\begin{array}{c}\text { Main } \\
\text { Performance } \\
\text { Objectives } \\
\text { (Clusters) }\end{array}$ & $\begin{array}{l}\text { Sub-items for } \\
\text { Each Main } \\
\text { Objective } \\
\text { (Criteria) }\end{array}$ \\
\hline \multirow{5}{*}{ COST } & $\begin{array}{l}\text { Cost } \\
\text { consumables (C1) }\end{array}$ \\
\hline & $\begin{array}{l}\text { Cost of quality } \\
\text { (C2) }\end{array}$ \\
\hline & Cost of labor (C3) \\
\hline & $\begin{array}{l}\text { Cost of equipment } \\
\text { (C4) }\end{array}$ \\
\hline & Penalty cost (C5) \\
\hline \multirow{4}{*}{ QUALITY } & Accidents (Q1) \\
\hline & Inspection (Q2) \\
\hline & TAT (Q3) \\
\hline & $\begin{array}{l}\text { Errors during the } \\
\text { testing procedure } \\
\text { (Q4) }\end{array}$ \\
\hline \multirow{7}{*}{$\begin{array}{c}\text { RESOURCE } \\
\text { MANAGEMENT }\end{array}$} & $\begin{array}{l}\text { Inventory Control } \\
\text { (RM1) }\end{array}$ \\
\hline & Ordering (RM2) \\
\hline & $\begin{array}{l}\text { Consumption } \\
\text { (RM3) }\end{array}$ \\
\hline & MTBF (RM4) \\
\hline & $\begin{array}{l}\text { The workload of a } \\
\text { machine (RM5) }\end{array}$ \\
\hline & $\begin{array}{l}\text { The workload of } \\
\text { staff (RM6) }\end{array}$ \\
\hline & $\begin{array}{l}\text { Maintenance of a } \\
\text { machine (RM7) }\end{array}$ \\
\hline \multirow{5}{*}{ TIME } & $\begin{array}{ll}\text { Order } & \text { entry } \\
\text { process time (T1) }\end{array}$ \\
\hline & $\begin{array}{l}\text { Specimen } \\
\text { collection and } \\
\text { delivery time (T2) }\end{array}$ \\
\hline & $\begin{array}{l}\text { Testing process } \\
\text { time (T3) }\end{array}$ \\
\hline & $\begin{array}{l}\text { Reporting process } \\
\text { time (T4) }\end{array}$ \\
\hline & $\begin{array}{l}\text { Accession } \\
\text { (T5) }\end{array}$ \\
\hline
\end{tabular}

\subsection{Pairwise Relation and Comparison}

To generate the network, relationships between clusters and between variables (the clusters and variables are listed in Table 2) are identified by three experts; one of these experts is a CL specialist, the other one is a manager from a university hospital, and the third one is a decision-maker in a private CL. The judgments of experts are combined and reduced to a single causal link (relationship) based on the most selected judgments (answers) by the experts. Refined relations among the criteria are shown in Figure 3.

These refined relations are transformed into a pairwise relation matrix (combined pairwise relation matrix) to obtain cluster and criteria weights and then into a network model.

SuperDecisions software was used for ANP analysis to make decisions with dependence and feedback relations [31]. These feedback and dependence relations can be in different levels of hierarchy but also they can be between elements at the same level [32]. The network hierarchy model was developed with clusters, nodes, and node connections as shown in Figure 4 [10].

The mathematical theory is based on the matrices for decision making developed by Thomas L. Saaty and eigenvectors that are used to develop a pairwise comparison matrix and it includes the priorities of nodes [33]. To develop the network model, each cluster and criterion under these clusters were created. Then, relation paths were mapped for each criterion, and finally, the overall network of the model is generated. Figure 4 illustrates the generic network view of the study.

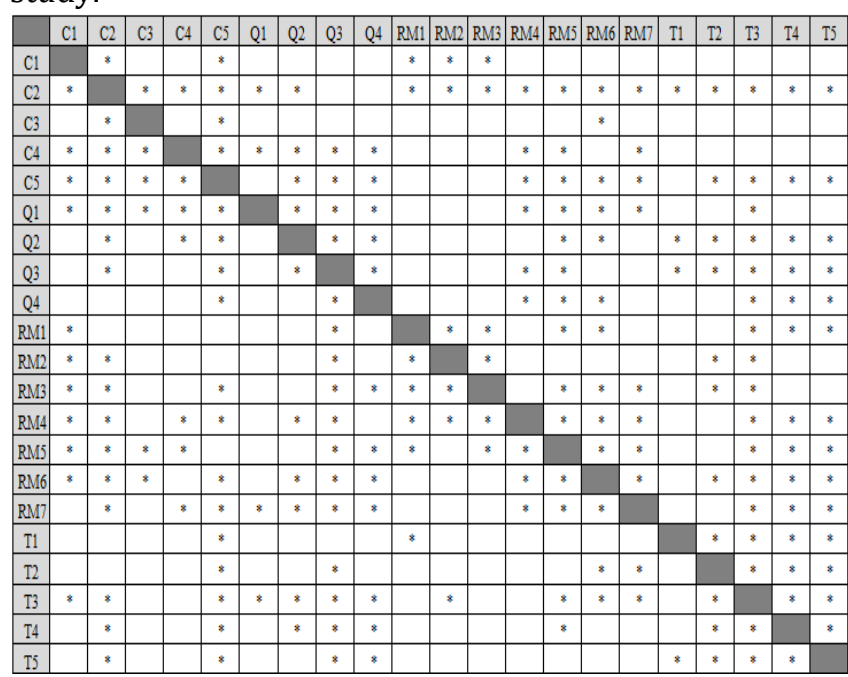

Figure 3. Pairwise relation matrix.

However, SuperDecisions software permits the modelers to define only one pairwise comparison matrix. Therefore, opinions of different experts are aggregated in one comparison matrix (aggregated pairwise comparison matrix) which is developed by taking the geometric mean of each judgment point given in the pairwise relation matrix. Figure 3 demonstrates the interpretation of Table 3 on SuperDecisions Software. In ANP, the networks are used to define effective elements about the problem. Influence networks indicate the factors and these networks are decomposed into clusters [14,34]. The linkages in Figure 4 are used to illustrate relations or dependencies among networks or within a network. These dependencies are classified as 'inner' and 'outer' dependencies. If the link indicates a relationship 
between the elements under the same parent, it is called 'inner dependency'. If this link is used to reflect a relationship between elements of different parents, it is named 'outer dependency'. The feedback relation can be examined under the condition of outer dependency. These inner and outer dependencies help us in the proposed framework to redevelop and enhance the relations among the key variables in conceptual model design.

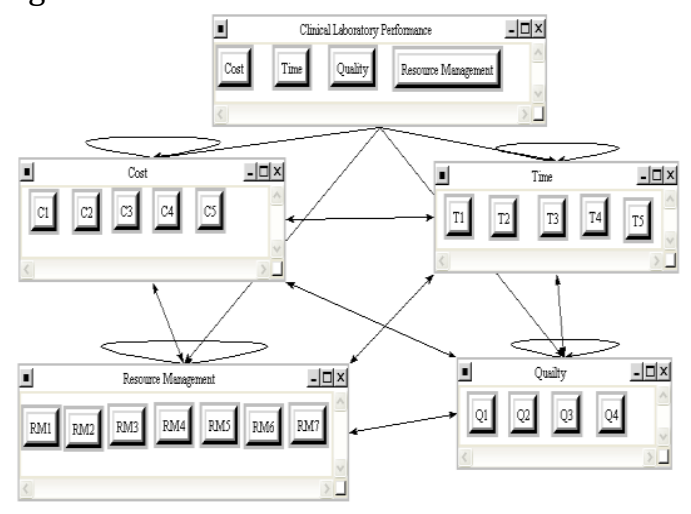

Figure 4. Obtained model view on SuperDecisions.

Combined pairwise relation matrix and aggregated pairwise comparison matrix are utilized and unweighted, and limiting matrices are calculated. Table 3 shows the relative importance results on clusters (cost, quality, resource management, and time) for CL performance.

Table 3. Importance weights of clusters.

\begin{tabular}{cc}
\hline Criterion Name & $\begin{array}{c}\text { Importance } \\
\text { Weights }\end{array}$ \\
\hline Quality & 0.384729 \\
\hline Time & 0.312121 \\
\hline Cost & 0.193316 \\
\hline Resource Management & 0.109835 \\
\hline
\end{tabular}

The results of Table 3 show that quality and time are the most influential variables on CL performance. Although cost and resource management are effective, their weights are less than quality and time as main indicators. The impact of each criterion is also important to prioritize the CL performance indicators. The overall importance of influential variables (criteria) on the goal can be calculated by normalizing the overall importance of clusters and the importance of each criterion under these clusters. The weights of these variables are not needed for the structural validity of the simulation model. However, they would be useful to generate strategies on an SD simulation model.

\subsection{Structural Validity}

As seen in the proposed framework (Figure 1), structural validity in SD modeling is composed of boundary adequacy, structure parameter verification analysis, dimensional consistency check, and extreme condition testing [35].
Although both extreme condition testing and dimensional consistency testing are important for structural validity analysis, they both are conducted after the dynamic model is developed. On the other hand, boundary adequacy, structure, and parameter verification analyses are performed after the conceptual model is developed. Since the main purpose of this paper is to support the conceptual model development and validation, only boundary adequacy, structure, and parameter verification analyses are performed. The procedure followed is explained in the following sections in detail.

\subsubsection{Boundary Adequacy Test}

In the boundary adequacy test, modelers check whether their model includes all essential concepts related to their problem or not. In our study, the boundary adequacy of the model is determined by both the literature review on CL performance and the ANP study. The key concepts for performance management captured through literature (resource, time, quality, and cost) were found to be suitable by experts to model the CL performance management system. These main concepts were then decomposed into sub-items in the ANP study. In pairwise relation and comparison matrices, experts had a chance to evaluate each subitem to determine the importance of each item.

\subsubsection{Structure Verification Test}

The main concern in structure verification or assessment is to ensure that the model structure is consistent with relevant descriptive information about the system. This descriptive knowledge should cover interrelations among the key variables proposed in the conceptual model. In our study, consistency and adequacy of the model structure are ensured with ANP model results. Our initial conceptual model was also shown to experts and their opinions were gathered to enrich and modify our model as mentioned in the 'Proposed Framework' section.

Experts emphasized the importance of labor especially in the pre-analytical (processes between test order request and analysis) and the post-analytical (report preparation and recording) phases during the ANP study. The analytical phase was performed by the machines automatically. Based on their feedback, the model was revised. In the prior design, the quality was only associated with errors during the testing procedure. However, experts stated that the qualified sample rate was also an important variable during the procedures. Although the rate and severity of accidents are very low, experts state that it can be used as an exogenous variable for the analysis. Based on the results of the ANP model and the modelers' observations/comments, the initial conceptual model was enriched and revised (Figure 4). 


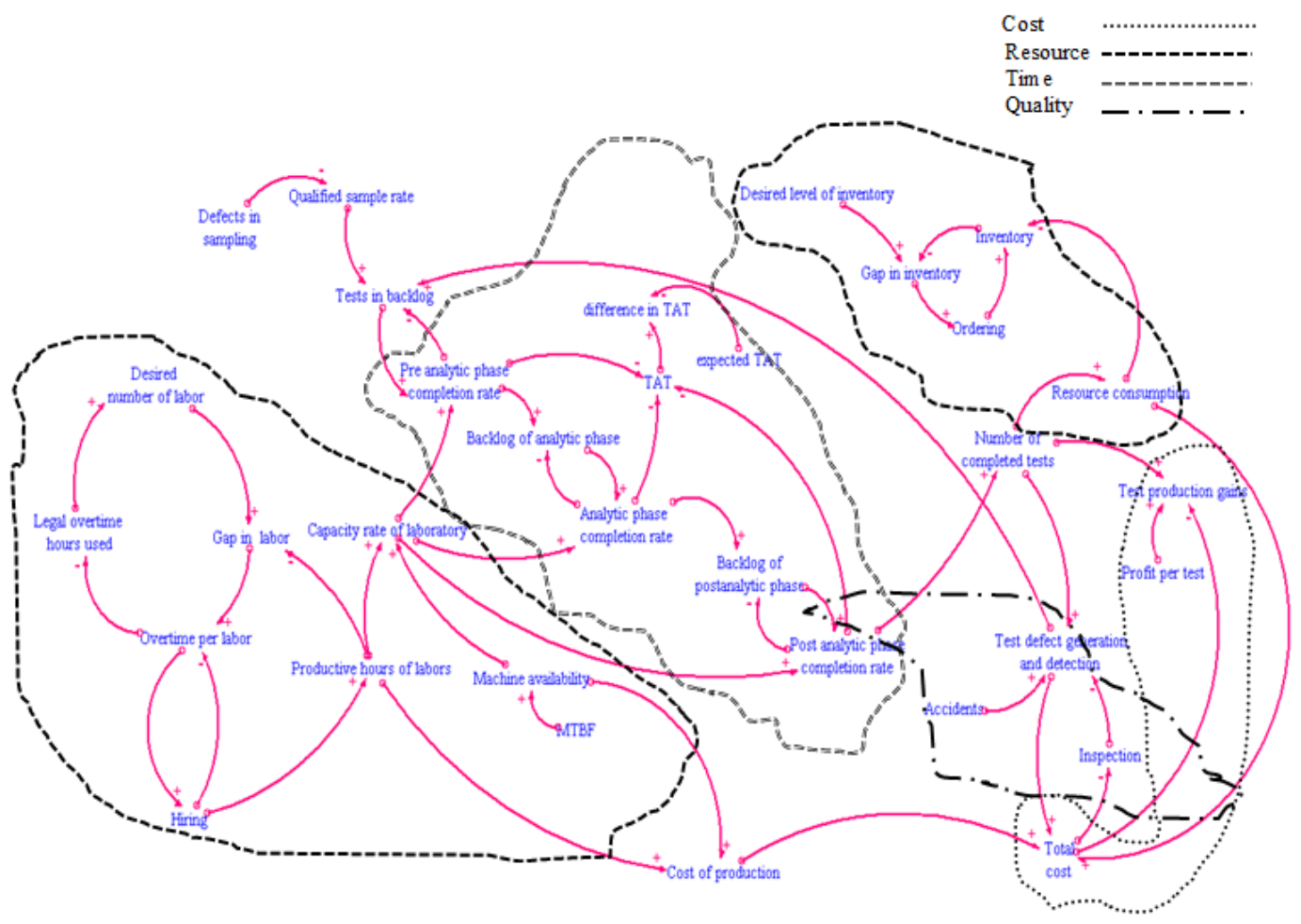

Figure 5. The validated conceptual model with ANP approach.

\subsubsection{Parameter Verification Test}

In the parameter verification stage, the main concern of the modeler is to ensure parameters included in the model are consistent with real-life (all parameters that took place in the model have real-world counterparts). The parameters in this study are gathered from a local CL. During the ANP model development, these parameters together with the conceptual model were shown to experts to verify their applicability in real-life.

\subsubsection{Other Structural Validity Tests}

As mentioned before, dimensional consistency and extreme condition tests are not covered in this study. One of the reasons is that dimensional consistency is ensured only after model parameter units are included in the dynamic model. Additionally, extreme condition tests can be performed only after dimensional consistency is ensured. Dynamic simulation model development is not part of this study. Thus, the dynamic model and its dimensional consistency and extreme condition verification tests are not included in the study.

\section{Discussion}

ANP methodology was utilized to generate a structured (formalized) discussion with the experts and to ensure the structural validation of a CL performance management system.

During the ANP study, experts emphasized the importance of labor in a CL performance system especially in the pre-analytical and the post-analytical phases. Based on their feedback, the conceptual model was revised (Figure 5). In the prior design, quality had only been associated with errors during the testing procedure (Figure 2). However, experts stated that a qualified sample rate is also an important variable during the procedures. Although the rate and severity of accidents were very low, experts stated that it can be used as an exogenous variable for the analysis. This information is included in the revised conceptual model (Figure 5). Another concern of experts was about inventory. They stated that the desired level of inventory should be set by the CL management. While a one-month stock level was accepted as adequate for private CLs, public CLs preferred a two-month stock level, which was included in the revised model. In addition, experts emphasized the importance of a training period for new hires, which is nearly three months. Although each new hire has a license to perform tests, they are not permitted to be involved in the testing process until their training time is over. The initial conceptual model was revised including this information.

From a multi-methodology perspective, an integrated framework design based on the combined use of a conceptual modeling method CLD and ANP method provides more value than each method considered individually. Thus, our study reports empirical evidence that agrees with the theoretical assumption that individual methodologies within a multi-methodology complement each other $[7,9]$.

Healthcare system simulations require the modeling of systems with complex behavior, thus conceptualization and validation of such simulation models are often difficult requiring the involvement of many stakeholders with opinions and objectives. Preferences of the modelers are believed to be highly effective on 
model conceptualization and validation. Researchers state that model conceptualization and/or validation is related to the cultural background of the modeler and model users [36]. Thus, collaboration with experts and decision-makers will create more realistic solutions. To ensure this collaboration, ANP provides a structured approach to collect expert opinions and to ensure all given inputs are considered and weighted properly.

Additionally, the use of the ANP method creates an opportunity to reflect interrelations among various criteria (variables) and can accommodate to ensure complex interdependencies, and feedbacks among system variables for conceptual model validation are captured. Thus, ANP provides completeness and deeper insights into the SD simulation validation.

ANP can be also beneficial to determine the relative importance results on clusters (cost, quality, resource management, and time) for CL performance. The impact of each criterion is important to prioritize the CL performance indicators. To weigh up the strategies and policies, a modeler tries to find a better model behavior experimenting with various key variables. In some cases, these variables generate conflicts. When such a problem is faced, a modeler must trade-off some of these variables. The overall weights of variables derived from pairwise comparison matrix results (ANP results) can be a practical way to determine the critical variables for the trade-off.

\section{Conclusion}

This paper presents a multi-methodology approach to develop a framework to combine ANP and SD methodologies. The proposed framework presents the ANP approach to be used to ensure the structural validity of CLD in a SD simulation model. ANP is a methodology that can be used to analyze pairwise relations among system variables in a static manner.

Thus, interrelations and dependencies among system components and their relative importance are determined based on expert opinions using ANP. These interrelations are then used to validate the initial conceptual model (CLD) of the SD model.

The proposed framework was used in a case study that is about one of the essential parts of the healthcare system, CLs. CLs are accepted as an important part of healthcare facilities. High demands on healthcare systems lead to the need for more sophisticated management systems. To create a tangible management system, CL performance indicators must be defined and prioritized properly. Understanding these indicators and analyzing their interrelations are believed to be necessary to create a sustainable CL performance management system. This study provides this analysis; with the help of ANP, pairwise relations among CL performance indicators were analyzed and mapped accordingly.

To the best of our knowledge, this is the first study that utilized ANP approach to conduct structural validity for a SD model, to prioritize CL performance indicators, and to capture their relations. Although the prioritized indicators were not needed as part of the conceptual model development, as future work, once the dynamic model is developed they can be utilized for policy analysis and strategy development purposes.

\section{References}

[1] Sargent, R. G. "Verification and validation of simulation models", Journal of Simulation, 7(1), 1224. 2013.

[2] Barlas, Y. "System dynamics: systemic feedback modeling for policy analysis", System, 1, 59, 2007.

[3] Balci, O., and Ormsby, W. F. "Conceptual modeling for designing large-scale simulations", Journal of Simulation, 1(3), 175-186, 2007.

[4]Groesser, S.N., and Schaffernicht, M. "Mental Models of Dynamic Systems:Taking Stock and Looking Ahead", System Dynamics Review, 28(1), 46-68, 2012.

[5] Maani K.E., and Cavana. R.Y., Systems thinking. System Dynamics: Managing Change and Complexity. Pearson Education: North Shore City, New Zealand, 2007.

[6] Chick, S.E., "Six ways to improve a simulation analysis", Journal of Simulation, 1(1), 21-28, 2006.

[7]Kunc, M., "Using systems thinking to enhance strategy maps", Management Decision, 46(5), 761778, 2008.

[8] Mingers, J., "Variety is the spice of life: Combining soft and hard OR/MS methods", International Transactions in Operations Research, 7(6), 673-691, 2000.

[9] Henao, F., and Franco, L. A., "Unpacking multimethodology: Impacts of a community development intervention", European Journal of Operational Research, 253(3), 681-696, 2016.

[10] Sterman, J.D., Business Dynamics: Systems Thinking and Modeling for a Complex World, Irwin McGrawHill, Boston, 2000.

[11] Barlas, Y., "Model validation in system dynamics", In Proceedings of the International System Dynamics Conference, 1994, pp. 1-10.

[12] Kumar, S., and Nigmatullin, A., "A system dynamics analysis of food supply chains-Case study with nonperishable products", Simulation Modeling Practice and Theory, 19(10), 2151-2168, 2011.

[13]Chwif, L., Muniz, P. S., and Shimada, L. M., “A prescriptive technique for $\mathrm{V} \& \mathrm{~V}$ of simulation models when no real-life data are available: Results rom a real-life project", Journal of Simulation, 2(2), 81-89, 2008.

[14]Karpak, B., and Topcu, I., "Small medium manufacturing enterprises in Turkey: an analytic network process framework for prioritizing factors affecting success", Int. J. Production Economics, Vol. 125, No. 1, pp.60-70, 2010.

[15] Saaty, T.L., and Peniwati, K., Group decision making: drawing out and reconciling differences, RWS 
Publications, 4922 Ellsworth Avenue, Pittsburgh, PA 15213, 2008.

[16] Saaty, T.L., "Analytic network process", in S.I. Gass and C.M. Harris (Eds.), Encyclopedia of Operations Research and Management (100th ed.). USA: Boston, pp.28-35, 2001.

[17] Fottler, M. D., "Health care organizational performance: Present and future research", Journal of Management, 13(2), 367-391, 1987.

[18]Arah, O. A., Klazinga, N. S., Delnoij, D. M. J., Ten Asbroek, A. H. A., and Custers, T., "Conceptual frameworks for health systems performance: a quest for effectiveness, quality, and improvement", International Journal for Quality in Health Care, 15(5), 377-398, 2003.

[19] Veillard, J., Champagne, F., Klazinga, N., Kazandjian, V., Arah, O. A., and Guisset, A. L., "A performance assessment framework for hospitals: the WHO regional office for Europe PATH project", International journal for quality in Health Care, 17(6), 487-496, 2005.

[20] Organisation for Economic Co-Operation and Development (OECD): In Towards High-Performing Health Systems, Edited by Organisation for Economic Co-Operation and Development. Paris. ISBN 9789264015555, 2004.

[21] Snozek, C., Kaleta, E., and Hernandez, J. S., "Management structure: Establishing a laboratory utilization program and tools for utilization management", Clinica Chimica Acta, 427, 118-122, 2014.

[22] Zinn, J., Zalokowski, A., and Hunter, L., "Identifying indicators of laboratory management performance: a multiple constituency approach", Health Care Management Review, 26(1), 40-53, 2001.

[23] Arah, O. A., Westert, G. P., Hurst, J., and Klazinga, N. S., "A conceptual framework for the OECD health care quality indicators project", International Journal for Quality in Health Care, 18(suppl 1), 5-13, 2006.

[24] Scinto, L.D., Product cost analysis in the clinical laboratory. Issues in cost accounting for health care organizations, Finkler SA (ED): Aspen Publishers INC Gaithersburg., 1994.

[25] Medical laboratories - requirements for quality and competence. Geneva, Switzerland: International Organization for Standardization, ISO 15189, 2012.

[26] Plebani, M., Astion, M. L., Barth, J. H., Chen, W., de Oliveira Galoro, C. A., Escuer, M. I., and Shcolnik, W., "Harmonization of quality indicators in laboratory medicine. A preliminary consensus", Clinical Chemistry and Laboratory Medicine (CCLM), 52(7), 951-958, 2014.

[27] Yenice, S., "Implementing a resource management program for accreditation process at the medical laboratory", Clinical biochemistry, 42(4), 266-273, 2008.
[28] Lundberg, G. D., "Acting on significant laboratory results", Jama, 245(17), 1762-1763, 1981.

[29] Azadmanjir, Z., Torabi, M., Safdari, R., Bayat, M., and Golmahi, F. A., "Map for Clinical Laboratories Management Indicators in the Intelligent Dashboard", Acta Informatica Medica, 23(4), 210, 2015.

[30] Hawkins, R. C., "Laboratory turnaround time", The Clinical Biochemist Reviews, 28(4), 179, 2007.

[31]http://www.superdecisions.com/super-decisionsdownload-page/ the SuperDecisions software.

[32] Tosun, O. K., Gungor, A., and Topcu, Y. I., "ANP application for evaluating Turkish mobile communication operators", Journal of Global Optimization, 42(2), 313-324, 2008.

[33] Saaty, T. L., and William, A., Super decisions software, Pittsburgh, PA: RWS Publication, 2004.

[34] Hamurcu, M., Gür, Ş., Özder, E.H., and Eren T.A., "A Multicriteria Decision Making for Monorail Projects with Analytic Network Process and 0-1 Goal Programming", International Journal of Advances in Electronics and Computer Science, 3(7), 8-12, 2016.

[35]Forrester, J. W., and Senge, P. M., "Tests for building confidence in system dynamics models", System dynamics, TIMS studies in management sciences, 14, 209-228, 1980.

[36] Qudrat-Ullah, H., and Seong, B.S., "How to do structural validity of a system dynamics type simulation model: the case of an energy policy model”, Energy Policy, 38(5), 2216-2224, 2010. 